Chapter 10

\title{
Disaster Risk Management and Social Impact Assessment: Understanding Preparedness, Response and Recovery in Community Projects
}

\author{
Raheem A. Usman, F.B. Olorunfemi, G.P. Awotayo, \\ A.M. Tunde and B.A. Usman
}

Additional information is available at the end of the chapter

http://dx.doi.org/10.5772/55736

\section{Introduction}

Disaster refers to an emergency caused by natural hazards or human-induced actions that results in a significant change in circumstances over a relatively short time period. Typical examples are death, displacement, disease, and loss of crops. Others may include damage to physical infrastructure, depletion of natural and social capitals, institutional weakening and a general disruption of economic and social activity. Disasters may differ somewhat in the trigger, scope, duration and requisite actions (Coletta, 2004, Olorunfemi and Raheem, 2007).

The global scenario in relation to disasters is dismal. World statistics indicate present and future trends of increasing impacts from natural and human made hazards on life and livelihoods (Niekerk, 2002; Ojo, 2003). During the past four decades, hazards events such as earthquakes, drought, floods, storms, fires and volcanic eruptions have caused major loss of human life and livelihoods; destruction of economic and social infrastructure and significant environmental damage. According to Gavidia (2000), natural disasters such as earthquakes, floods and hurricanes can wipe out years of urban development by destroying infrastructure and housing and by injury or killing thousands of people. The 2011 Tsunami in Japan is an example of a disaster characterized by an immense loss of lives and property.

Social and economic structure of a society is a major determinant of the vulnerability of the population to the impact of disasters. This explains the variation in the impact of disasters and environmental emergencies all over the world. The Munich Re-insurance estimated that economic losses due to environmental emergencies have increased three-fold from the 1960s to the 1990s, and in the first few years of this decade, are running about US $\$ 50$ billion per year. 
Although most of these economic losses occurred in industrially developed parts of the world developing countries in Africa and Asia suffer greater burden of the relative impact of these disasters. The effects of disasters on such human and economic sectors as employment, balance of trade, indebtedness from reconstruction and loss of capital continued to be felt for many years after disaster events (CERD, 2000; Mac Entire, 2001).

Developing nations in particular, experience pervasive risk of devastation, human and property loss resulting from human and natural disasters (Gbadegesin, et al, 2010). According to Henderson (2004), this level of risk is attributable to socio-economic stress, aging and inadequate physical infrastructure, weak education and preparedness for disaster and insufficient fiscal and economic resources to carefully implement the preparedness, response, mitigation and recovery components of integrated emergency management.

Disaster risk is a potential factor in many development projects. Environmental hazards can affect a project area, with socio-economic consequences for the project's target populations. Development projects can increase or reduce the risk of natural disaster, through their impact on social resilience and the natural environment. By understanding and anticipating future hazard events, communities, public authorities and development organisations can minimise the risk disasters pose to socio-economic development. Understanding the interactions between projects and environmental hazards is crucial in ensuring the sustainability of development gains. Sustainable development is accepted as a fundamental objective for public policy and decision making because the overall objective of any development process is to enhance the quality of life of the target population. Thus the growing acceptance of sustainable development as an over-arching policy goal has rightly stimulated interest in assessing the impact of particular intervention on sustainable development at aggregate, sectoral or project levels (Centre for Good Governance, 2006). This sustainability objective is justified based on the fact that issues pertaining to the ecosystem's capacity to tolerate and respond to population growth and other human induced stresses have become essential for sustainable management of natural resources and human livelihood systems related to them.(Uito and Morgan, 1996). Thus due to increased pressure on resources accompanied by evidence of environmental deterioration, poverty inequality, and general economic decline needed to be addressed in regards to the immediate or potential environmental damage and social consequence that may be associated.

Social impact assessment can therefore play an important role in the understanding of the consequences and social outcome of projects that are meant to tackle poverty, enhance community development or designed to reduce vulnerability to disasters during environmental emergencies.. According to the Inter-organizational Committee of the U.S. Department of Commerce National Oceanic and Atmospheric Administration National Marine Fisheries Service (1994), "social impacts" refers to the consequences to human populations of any public or private actions-that alter, or are capable of altering, the ways in which people live, work, play, relate to one another, organize to meet their needs and generally cope as members of society. The term also includes cultural impacts involving changes to the norms, values, and beliefs that guide and rationalize their cognition of themselves and their society. Social Impact Assessment (SIA) is the process of analysing, monitoring and managing the social consequen- 
ces of policies, programmes and projects. These consequences may be positive or negative, intended or unintended, direct or indirect; they may be short-term impacts or long-term changes. As well as helping to explain how a proposed action will change the lives of people in communities, SIA indicates how alternative actions might mitigate harmful changes or implement beneficial ones.

The rest of this paper is subdivided into four sections. After this introduction the next section is devoted to the clarification and definition of major conceptual issues with a view to establishing a link between each of the concepts and providing a framework for the entire paper. We also provide a discussion on the ways disaster risk can be minimised in community development projects. The next two sections in the paper examine respectively the livelihood contexts in disaster management and the need for a process that integrate disaster risk into community projects through social impact assessment. In this section, the paper provides a typical example from previous projects. The SIA process is also discussed as a series of interrelated steps and how hazards and disaster risk typically require a SIA. Finally the last section is devoted to examining the critical challenges to the success of adoption of SIA in community projects.

\section{Some conceptual issues in disaster risk management}

Conceptually, the relationship between vulnerability, hazard and disasters has been described as the Pressure Model or Disaster Crunch Model by Blaikie et al (1994). These experts claim that vulnerability progresses in the following three states:

- Underlying (remote) causes: a set of deep-rooted factors within a society that interact synergistically to form and maintain vulnerability.

- Dynamic pressures: this represents a process which channels the effects of negative cause into unsafe conditions. For instance, a lack of basic services at the household level or due to a set of macro-forces.

- Unsafe conditions: this stage is the vulnerable context where people and/or property are exposed to disaster risk. An example is the construction of shanty buildings on fragile or sloppy urban land.

Disaster management aims at motivating societies at risk to be more involved in the conscious management of risk and reduction of vulnerability in our various communities. As a cross cutting issue, it demands substantial commitment from public authorities/ Civil society and a greater inter-sectoral and policy coordination at all levels. This section provides a clarification of some terms used in disaster management.

\subsection{Hazard}

A hazard can be defined as a potentially damaging physical event, phenomenon or human activity which may cause the loss or life or injury, property damage, social and economic 
disruption or environmental degradation. Hazards can include hidden conditions that may represent future threats and can have different origins. These include natural (geological, hydro-meteorological and biological) and/or induced by human processes (environmental degradation and technological hazards) (ISDR 2002: 24).

According to Niekerk (2002) hazards can be single, sequential or combined in their origin and effects.

Each hazard is characterized by its location, intensity and probability. Typical examples of hazards can be the absence of rain (leading to drought) or the abundance thereof (leading to flooding). Chemical manufacturing plants near settlements can also be seen as hazards.

Similarly, incorrect agricultural techniques will in the long run lead to possible disasters such as loss of crops and famine. Hazards can either be a creation of humans or the environment. Although the farmer can be planned for than the latter, in both cases, the management of hazard will remain the same.

\subsection{Vulnerabilities}

Vulnerabilities is a set of prevailing or consequential conditions resulting from physical, social, economic and environmental factors, which increase the sustainability of a community to the impact of hazards (ISDR 2002: 24). It can comprise of physical, socio-economic, environmental and/or political factors that adversely affect the ability of communities to respond to events (Jegillos, 1999). Blaike et al (1994) is of the opinion that vulnerability is the characteristics of person or group in terms of their capacity to anticipate, cope with, resist and recover from the impact of a hazard.

Vulnerability can be expressed as the degree of loss resulting from potentially damaging phenomenon or hazard (Niekerk, 2002). In other words, vulnerabilities can be measured by the level of fatality i.e. amount of deaths, losses of properties or cash etc. Population increases due to high birth rate and the lack of good governance do make communities in developing nations to be highly vulnerable to hazards.

The community and its members may or may not be willing participants in contributing to or tolerating the conditions leading to vulnerability. Taken together, they create a dynamic mix of variables, each of which results from a continuous process. Vulnerabilities can be physical, social or attitudinal and can be primary or secondary in nature. If there are positive factors, that increase ability to respond to needs effectively or which reduce susceptibility, they are considered capabilities or coping mechanics.

Aspects contributing to vulnerability:

- Political factors

- Economic factors

- Physical factors

- Social factors 


\section{- Ecological factors}

\subsection{Risk}

Risk is usually associated with the inability of people to manage hazard events that may eventually lead to negative consequences like destruction of the environment, socio-economic activities, properties and losses of lives.

Risk in terms of disaster management has a specific focus (UN, 1992). It can be defined as the probability of harmful consequences (ISDR, 2002), or expected losses (lives lost, persons injured, damage to property and/or the environment, livelihoods lost, disruption of economic activity or social systems) due to the interaction between humans, hazards and vulnerable conditions. Risk is therefore the possibility that a particular hazard might exploit a particular vulnerability (Nierkerk, 2002).

It is the production of the possible damage caused by a hazard due to the vulnerability within a community. In other words, risk is usually due to hazard events exploiting the vulnerable situation of an environment or community. The poorer communities are more at risk because of their high vulnerability to hazard situations due to their low coping capacities. The perception of risk and causes vary from community to communities and culture to cultures.

Two elements are essential in the formulation or risk: the probability of occurrence of a given threat (e.g. a hazard); and the degree of susceptibility of the element (e.g. a rural community) exposed to that source (vulnerability (ISDR, 2002: 41).

\subsection{Disasters}

A disaster is a serious disruption of the functioning of a society, causing or threatens to cause, widespread human, material, or environmental losses which exceed the ability of affected community to cope using only its own resources (South Africa, 2002). Disasters can be sudden (flash floods) or progressive (drought). Disasters are caused due to the interaction of humans with their environment.

A disaster is a function of the risk process. It results from the combination of hazards, conditions of vulnerability and insufficient capacity or measures to reduce the potential negative consequences of risk (ISDR, 2002: 25).

Extreme natural phenomena do not in themselves constitute hazards. It is only when such phenomena occur in an environment where they pose a threat to human life, property, infrastructure or the environment that they can be classified as hazards. Similarly in the case of technological developments, it is only when such developments pose a danger e.g. industrial accidents, infrastructure failures. In essence, a disaster is the result of a hazard's impact on society. So the effects of a disaster are determined by the extent of a community's vulnerability to the hazard.

Hazards in themselves do not constitute disasters. The magnitude of disaster, according to Niekerk, is usually described in terms of the adverse effects which a disaster has had on lives, property and infrastructure; environmental damage; and the costs attached to post-disaster 
recovery and rehabilitation. Simply out, therefore, disaster risk is the product of the combination of three elements - vulnerability, coping capacity and hazard (ISDR, 2004). This interaction is illustrated in the following formula.

Disaster risk $(\mathrm{R})=\frac{\text { Vulnerability }(\mathrm{V}) \times \operatorname{Hazard}(\mathrm{H})}{\text { Capacity }(\mathrm{C})}$

Hazards are increasingly dynamic and with highly varying potential impacts. A wide range of geographical, meteorological hydrological, environmental, technological, biological and socio-political hazards can threaten livelihoods and sustainable development.

Hazards can be classified into three broad categories:

- Natural hazards

- Technological hazards

- Environmental degradation.

It should be noted that all communities be it rural or urban are vulnerable to hazards. However, different regions will be more prone to certain types of hazards than others.

Natural hazards are those triggered by climatic and geographical variability, which is at least partly beyond the control of human activity (Palm, 1990).

Technological hazards represents dangers originating from technological or industrial accidents, dangerous procedures, infrastructure failures or certain human activities, which may cause the loss of life or injury, property damage, social and economic disruption or environmental degradation.

Degradation of the environment is processes induced by human behaviour and activities (sometimes combined with natural hazards) that damage the natural resource base or adversely alter natural processes or ecosystems. Potential effects are varied and many contribute to an increase in vulnerability and the frequency and intensity of hazards.

The linkages between natural hazards and human-driven disasters and distressing environmental and humanitarian situations are increasingly present, particularly as the poor are compelled to exploit scarce environmental resources simply for survival. Deforestation, land degradation, and related food security are shaped by human resource use (e.g. urban squatting on marginalized hillsides), in turn sometimes creating conditions for flooding, landslides and drought.

To ensure an integrated approach by all relevant role players in assessing hazards and determining the risk and vulnerability in our communities, there is need for risk and vulnerability analysis. The following steps should be followed in order to engage in risk and vulnerability analysis.

- Identify the nature, extent, and risk of hazards;

- Determine the existence and degree of vulnerabilities;

- Identify the capabilities and resources available; 


\begin{tabular}{|l|}
\hline \multicolumn{1}{|c|}{ Natural Hazard $(\mathrm{NH})$} \\
Natural phenomena potentially \\
causing losses to human settlements \\
and economic activities
\end{tabular}

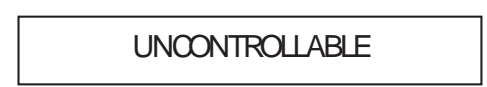

\section{Vulnerability (V)}

Susceptibility to human, economic an $\mathrm{d}$ financial losses resulting from the risk of natural disasters

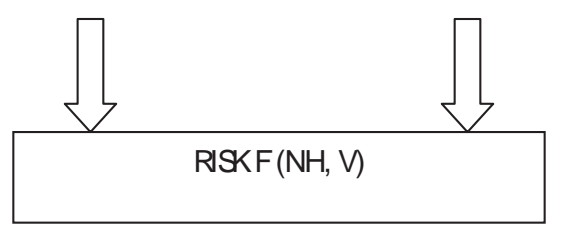

\section{CONTROШABLE}

Source: Keipi and Tyson, 2002

Figure 1. Natural Hazard, Vulnerability and Risk

- Determine the acceptable levels of risk, cost-benefit considerations;

- Develop methods Set priorities relative to time, resource allocation effectiveness of results;

- to protect people and key resources and reduce overall losses;

- Design effective and appropriate management systems to implement and control.

The strategies that can be used for the improvement of the application of risk and vulnerability analysis, according to Niekerk (2002) include the following:

1. Include analysis of natural hazard risk as part of on-going natural resource evaluation and development strategy formulation (in terms of integrated development planning and projects) (see Figure 2).

2. Identify and formulate mitigation measures for development investment project.

3. make information on natural hazard and community vulnerability more widely available more accessible to emergency response and development planning departments.

4. Train planning technicians and decision-makers in hazard assessments, vulnerability analysis, and disaster mitigation appreciation and techniques.

5. Review risk perceptions of different economic groupings, (e.g. farmers, fishermen, small business community, labourers etc.).

6. Special emphasis on "lifeline systems" vulnerability analysis.

7. energy sector vulnerability in relation to natural hazard.

8. Floor hazard assessment and early flood alert systems as part of integrated development (or agricultural) projects. 
9. Include hazard assessment and vulnerability reduction measures as a part of provincial and local development plans.

10. Include landslide hazard and vulnerability assessments in metropolitan areas and on critical transportation routes.

11. Use of geographical information systems in national, provincial, and local government level analysis of natural hazards, resources, populations, critical facilities, infrastructure.

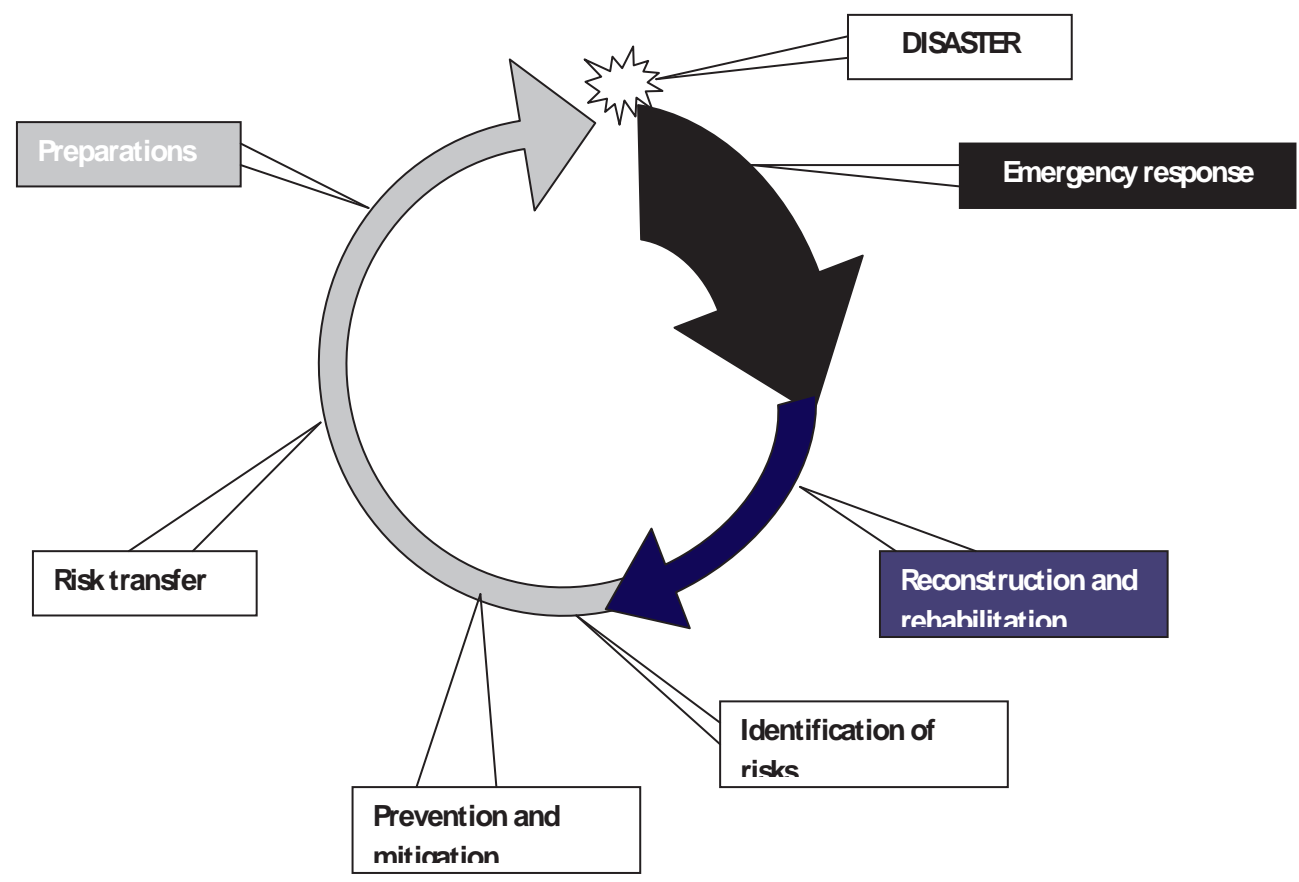

Source: Keipi and Tyson, 2002

Figure 2. Risk Management as a Virtuous Circle

\section{Risk identification and analysis}

To identify the risk of natural disasters at an individual, local or national level, it is necessary to estimate the potential magnitude and probability of natural hazards, as well as to estimate the potential magnitude and probability of natural hazards, as well as to evaluate the vulnerability of each of them. According to Keipi and Tyson (2002), vulnerability may be evaluated from various standpoints (physical, social, political, technological, institutional, environmental, cultural and educational). Vulnerability to natural disasters is the result of anthropogenic factors; that is, factors that result from the interaction between human beings and nature. 
Additionally, vulnerability is a consequence of the individual and political decisions that a society makes before a hazard occurs, which are evident once the disaster takes place (ECLACIDB, 2000).

Freeman, et al (2001), analyze the components of different types of vulnerability and cite studies that make an effort to measure the potential physical, social and economic consequences of natural phenomena. Those who concentrate on physical vulnerability analyze the impact on buildings, infrastructures and agriculture. For example, the Latin American's Council on Applied Technology publishes vulnerability studies on the earthquake resistance of 50 types of structures (ATC, 1985). Those who focus on social vulnerability estimate the impacts on especially susceptible groups such as the poor, pregnant women and infants, the handicapped, children and youths. Those interested in economic vulnerability calculate the potential impacts on economic processes and assets.

The results of the hazard analysis and of the evaluation of vulnerability are then combined to yield an estimate of risk (defined as expected loss per period) (Keipi and Tyson, 2002). A full scope evaluation of risk encompasses the appraisal of potential losses generated by the disaster and identification of those affected by the risk. The evaluation of the risk makes it possible to develop risk management strategies with two basic components:

i. prevention and mitigation actions to reduce potential human, social or economic losses; and

ii. measures to establish financial protection against the risks that cannot be reduced.

The availability of information is critical for any action aimed at reducing the impact of disasters. Projection of the likelihood of their occurrence and estimates of their impact allow decision makers to evaluate the total risk to a country, a geographical area or a specific sector, as well as to establish concrete prevention and mitigation measures and investments.

According to Keipi and Tyson (2002), prevention and mitigation actions require a good understanding of natural threats, vulnerability and risk. For example, given the frequency of disaster events that have occurred in Latin America and the Caribbean, on many occasions, investments in prevention and mitigation in the affected countries were not adequate to withstand the natural threats (see also Charveriat, 2002).

\section{Livelihoods context for disaster management}

While physical tangible assets such as stronger homes, hospitals etc are crucial to reducing risks from disasters, there are many less tangible assets which people depend on to recover and survive. For instance, following an earthquake disaster in India on 26 January 2001, an evaluation by the London-based Disasters Emergencies Committee (DEC), one villager said, "We received 2,000 tents for 900 households because we had a prominent politician in the community". Some villagers proved more capable than others in accessing aid for relief and reconstruction. Why? The DEC's evaluation found that "Women, lower income groups and 
those representing smaller number stated they were left out of decision-making in the relief committees and hence were also omitted from relief distribution".

The livelihoods - based approach to disaster reduction tries to unpack different aspects of vulnerability and capacity. It describes how people, both rich and poor, access the assets they need, how these assets are controlled and how assets are used both to improve livelihoods and to reduce vulnerability to disasters and "shocks" such as ill-health or unemployment. Tangible assets can be both physical (e.g. relief, safe housing) and financial (such as income, savings, insurance). However, non-tangible assets are just as important. They include alternative skills, training and disaster awareness (human assets); community organization, self-help and solidarity (social assets); representation in decision-making and the ability to lobby leaders for action (political assets). These non-tangible resources are often ignored by disaster managers, but prove pivotal in sustaining disaster preparedness, mitigation and rehabilitation. The nontangible assets which include skills training to improve earning opportunities, raising awareness of vulnerable people's right, building the capacity of self-help community groups, and strengthening the involvement of the poor in the decision-making process should be enhanced.

The livelihoods approach therefore sits on the cross-roads between disasters and development. It makes clear that disasters are part of everyday life, and must be overcome if livelihood is to be sustainable. Within this approach, disaster mitigation is in effect the act of building up tangible and non-tangible assets to reduce vulnerability. This leads to another key feature of the livelihoods approach which is the need to view vulnerable communities in a holistic rather than a sectoral way. The livelihoods approach sees people as the starting point of all interventions to reduce risk. People's lives are complex and do not fit nearly into the sectoral areas that aid practitioners specialize in. Solidarity among neighbours and their willingness to help in times of disaster, for example, is more valuable than the best drafted preparedness plan. By rooting risk reduction in a developmental context, livelihoods strategies enable disaster managers to take better account of the complex interaction of life that people themselves employ to mitigate, respond to and recover from disaster. According to WDR, 2001-2001, there are three key priorities in accounting for the complex interaction namely:

- Build non-tangible assets: Improving the skills, self-help and solidarity of households and communities will prove as important in the face of disaster as investing in physical and financial defenses.

- Strengthen everyday lives: Preparing for major disasters are only part of risk reduction. Smaller, ongoing disasters can over a period of time, take a heavier toll than big one-off disasters. So strengthening everyday lives by investing in human, social and political assets will help reduce the risk posed by a whole range of hazards, large and small.

- Listen to local priorities: The livelihoods approach puts vulnerable people and their priorities at the center of aid strategies. Despite much rhetoric, thus often doesn't happen. For instance, a London-based Disasters Emergencies Committee Evaluation in Gujarat India discovered people constantly emphasized the need to restore livelihoods rather than receive relief and expressed some frustration that outsiders did not listen to them on this point. They wanted 
to receive cloth and make their own clothes rather than receive clothing but no one took any notice.

\section{Integrating disaster risk into community projects through social impact assessment}

Sustainable development and disaster reduction are essential preconditions for each other. Natural disaster risk is a potential factor in many development projects. Environmental hazards can affect a project area, with socio-economic consequences for the project's target populations. Development projects can increase or reduce the risk of natural disaster, through their impact on social resilience and the natural environment.

Social impacts can be characterized and defined in many ways. The following definition is widely understood and used:

\footnotetext{
"By social impacts we mean the consequences to human populations of any public or private actions that alter the ways in which people live, work, play, relate to one another, organize to meet their needs and generally cope as members of society. The term also includes cultural impacts involving changes to the norms, values, and beliefs that guide and rationalize their cognition of themselves and their society."(Inter-organizational Committee on Principles and Guidelines for Social Impact Assessment, 2003).
}

SIA originated as a socio-economic component of environmental impact assessment (EIA), although it has since expanded and developed considerably, in developed and developing countries. SIAs can be carried out at different stages in project and policy development, from initial planning to implementation and post-implementation evaluation. In project-level assessment, typical applications include considering the likely impacts of new industrial activities, construction, land use or resource management practices. SIA often forms part of a broader social analysis or assessment, but has a distinct and more specific purpose.

As a conceptual model, SIA is equipped to take hazard and related disaster risk into account, whether these are external factors affecting a project or conditions created or magnified by the project itself. In general, SIA can be understood as a framework for evaluation of all impacts on humans and on all the ways in which people and communities interact with their sociocultural, economic and environmental surroundings.

By providing an understanding of the community and its social processes, SIA makes it possible to:

- identify the direct and indirect social consequences of risks (i.e., the social impacts which could arise from a hazard event); and 
- develop appropriate and effective mitigation mechanisms to hazards which harness community resources and recognize community reactions to events.

SIA theory accepts that social, economic and biophysical impacts are interconnected and that change in any one of these domains will lead to changes in the others. Seen in this way, SIA has clear linkages to EIA and other forms of ex-ante impact assessment, as well as with vulnerability and sustainable livelihoods analysis. Guidance on SIA makes it clear that good practice in project design and implementation is risk-averse.

However, while hazards and risk are important features of the SIA process, SIA is not specifically a risk assessment but a means of understanding and measuring human responses to situations that may be risky or threatening.

Therefore, SIA is not commonly used by itself as a method of analysing hazard risks generated by a project or external to it. It is more common for a formal risk analysis or a health impact assessment (see Box 2) to be undertaken, either to complement the SIA or within a broader EIA of which the SIA is part.

\section{Integrating hazard and disaster risk into the SIA process}

According to the Centre for Good Governance (2006), a conventional SIA process comprises the following ten steps, which are set out below with comments about how hazards and related disaster risks can be incorporated into the process.

\section{Step 1. Develop public involvement programme}

The first step is to develop an effective plan to involve the public. This requires identifying and working with all potentially affected groups. It should explicitly include those who might be exposed to greater (or lesser) hazard risk as a result of the project. Stakeholder engagement is vital to SIA and should take place throughout the assessment. This should involve genuine participation in the process, not merely consultation.

\section{Step 2. Describe proposed action and alternatives}

The proposed action or policy change (and alternative approaches, if appropriate) is described in enough detail to begin to identify the data requirements for an SIA and design the framework for assessment. Potentially key types of social impact, including those related to disasters, should be identified and plans made to obtain relevant data. This step is equivalent to the screening stage in an EIA.

\section{Step 3. Describe relevant human environment and zones of influence}

Relevant data on the geographical and human environments related to the project are collected and reviewed through a baseline study or community profile. This study could cover relationships between people and their biophysical environment (e.g., ecological setting, aspects of the environment seen as resources or problems, patterns of resource use) and culture, attitudes and social-psychological conditions (e.g., risk perception, psychological coping). 
Hazards and vulnerability should be factored into the baseline analysis.

\section{Step 4. Identify probable impacts (scoping)}

This stage seeks to identify the full range of possible social impacts (including those perceived by affected groups). Early, comprehensive and systematic screening can identify potential hazards and associated risks that might affect the project and communities at any stage in the project cycle, as well as the impact the project itself might have on disaster risk. It is important that the views of all affected people, including those vulnerable to hazards, are taken into account.

\section{Step 5. Investigate probable impacts}

Investigation of the social impacts identified during scoping is the most important component of the SIA. A range of methods, including modelling and scenarios, can be deployed to investigate probable future impacts. Hazardous events (as external factors or consequences of the project) and their risk or uncertainty should be included in trend and scenario analysis. As part of the latter, scenarios should be developed of the social consequences of exposure to the hazards identified (e.g., using fault- or event-tree procedures). 2 Records of previous experiences (including disaster events) provide valuable data for this process.

\section{Step 6. Determine probable response}

The responses of all affected groups to the impacts are assessed, in terms of attitude and actions. This should include responses to changes in social vulnerability as a consequence of the project and to a disaster event with an impact on the project. Differential vulnerability between social groups should be recognized.

\section{Step 7. Estimate secondary and cumulative impacts}

Secondary (indirect) and cumulative project impacts are assessed, although it is almost impossible to identify all dimensions of social impacts because of the way in which one change leads to others. Future patterns of vulnerability, both as long-term results of the project and due to other factors (e.g., climate change), should be considered in this stage.

\section{Step 8. Recommend changes or alternatives}

The consequences of changes to the plan or alternative interventions are assessed as in step 5 (though usually on a more modest scale) and the same key issues should be considered.

\section{Step 9. Mitigation, remediation and enhancement plan}

A plan is developed for mitigating adverse impacts, by not taking or modifying an action, minimizing its impacts through design and operational changes, or compensating for its impact by providing alternative facilities, resources or opportunities. This might include risk mitigation strategies. Impact avoidance should be the first priority, impact reduction or minimization undertaken if avoidance is not possible, and offsetting or compensation for adverse impact used only when no other options are available.

\section{Step 10. Develop and implement monitoring programme}


A monitoring programme is developed to track project or programme development and compare actual impacts with projected ones.

\section{Critical factors for success}

According to IPIECA (2004), the following factors may be important in making sure that social impacts associated with natural hazards are addressed through the SIA process:

- SIA should be linked to the rest of the appraisal process, especially to EIA and associated risk assessments, and the results of these different assessments related to each other in a comprehensive and coherent analysis of project impacts.

- Whilst a holistic view is essential, hazard and related risk issues should be kept in proportion, both with regard to their intrinsic significance and in relation to other social impacts.

- Impact assessment must feed back into project design, leading where necessary to development of avoidance or mitigation strategies.

- Communities' perceptions are important indicators of hazards and associated risks, and of their likely responses to project interventions.

- Affected communities should be fully involved in the assessment, not just as providers of information (i.e., public consultation), where their extensive knowledge of local hazards and risk management strategies will be valuable, but in negotiations with other stakeholders about avoidance or mitigation options.

- Positive benefits of projects in terms of reducing risk should be acknowledged.

- Findings should be communicated to decision-makers and acted upon by them - SIA is a tool to help make decisions.

\section{Conclusion}

When placed in the context of sustainable development, disaster management represents an important aspect of socio-economic and national security, therefore facilitating a continuous development process. Disaster reduction policies and measures need to be implemented with a two-fold aim; to increase the resilience to natural hazard while ensuring that development efforts do not increase vulnerability to these hazards.

It is important to emphasize that disaster risk reduction is a proactive approach that needs to be integrated in regular development planning and poverty reduction program at all levels. Policymakers in the development and poverty reduction sector need to recognize that disasters are not just "setbacks" or "roadblocks" to development, but result from the paths that development is pursuing. Thus by changing our planning processes, and incorporating disaster risk assessment in the planning of all new development projects, we can make sure 
that the future natural hazards will encounter resilient communities that are capable of withstanding their impact and therefore remain mere emergencies rather than disasters. We need to recognize that we can mitigate the impact of disaster and make mitigation the cornerstone of disaster management interventions. We must shift the focus to the most poor and vulnerable sections of our society, and ensure that our interventions are community-based and driven. To do this the extent to which a community disaster risk space is linked with environmental management practices must be recognized and given adequate consideration. For instance, during flood events, a sustainable risk reduction must take note of increased flood that is caused by the conversion of natural landscapes into agricultural areas such that flood mitigation does not jeopardize agricultural practices with an attendant risk of food insecurity. In essence, community participation is required since members of the community are directly affected by the disaster and are the ones who need to take decisions to reduce the risk; it is therefore unlikely that risk reduction will be successful without active involvement of the local community in the critical stages of disaster risk reduction efforts. Thus for sustainable risk reduction during disasters, particularly those that may lead, even if in the short-term, to reduced access to natural and environmental resources, local agreement must be sought and obtained to forestall a misinterpretation of the project intention by the local people for which the project is targeted.

\section{Author details}

Raheem A. Usman ${ }^{1}$, F.B. Olorunfemi ${ }^{2}$, G.P. Awotayo ${ }^{3}$, A.M. Tunde ${ }^{1}$ and B.A. Usman ${ }^{1 *}$

*Address all correspondence to: uadebimpe@unilorin.edu.ng

1 Department of Geography and Environmental Management University of Ilorin, Ilorin, Nigeria

2 Physical Development Department, Nigeria Institute for Social and Economic Research (NISER), Ibadan, Nigeria

3 School of Basic and Remedial Studies, Kwara State College of Education, Ilorin, Nigeria

\section{References}

[1] Blaikie, P, Cannon, T, Davis, I, \& Wisner, B. (1994). At Risk: Natural Hazards, People's Vulnerability, and Disasters.London: Routledge.

[2] Gbadegesin, A. S, Olorunfemi, F. B, \& Raheem, U. A. (2010). Urban Vulnerability to Climate 
[3] Change and Natural Hazards in Nigeria"In: Hans Günter Brauch, Ursula Oswald Spring, Czeslaw Mesjasz, John Grin, Patricia Kameri-Mbote, Bechir Chourou, Pal Dunay, Jörn Birkmann (Eds.): Coping with Global Environmental Change, Disasters and Security- Threats, Challenges, Vulnerabilities and Risks (Hexagon Book Series, BerlinHeidelberg- New York- Hong Kong- London- Milan- Paris- Tokyo: Springer-Verlag, (2010). , 5

[4] International Petroleum Industry Environmental Conservation Association IPIECA (2004) A Guide to Social Impact Assessment in the Oil and Gas Industry IPIECA..

[5] International Strategy for Disaster Reduction (ISDR) ((2002). Living with Risk: A Global Reviews of Disaster Reduction Initiatives Preliminary version. Geneva: ISDR Secretariat.

[6] International Strategy for Disaster Reduction (ISDR) ((2002). Background paper No.5 for WSSD. United Nations International Strategy for Disaster Reduction, (1)

[7] Jegillos, S. (1999). Fundamentals of Disaster Risk Management: How are South East Abian Countries Addressing this? In: Holloway, A Risk, Sustainable Development and Disasters. Southern Perspective. Cape Town: Periperi Publications.

[8] Keipi, K, \& Tyson, J. (2002). Planning and Financial Protection to Survive Disasters Inter-American Development Bank, Washington, D. C Sustainable Development Department Technical Papers Series

[9] Moor, J. (2001). Cities at Risk in Habitat Debate , 7(4)

[10] Niekerk, D. (2002). Disasters and Sustainable Development. African center for Disaster Studies. Potchefstroom University, South Africa.

[11] Ojo, E. E. (2003). Disasters and Sustainable Development: Some Reflections and African Perspective. Paper prepared for Certificate Course in Disaster Studies. ACDS, Potchestroom University, South Africa.

[12] Olorunfemi, F, \& Raheem, U. A. (2007). Urban Development and Environmental Implications: The Challenge of Urban Sustainability in Nigeria. The Australasian Review of African Studies Volume XXVIII 2006/2007 